\title{
REVIEW OF MONITORING AND EARLY WARNING TECHNOLOGIES FOR COVER-COLLAPSE SINKHOLES
}

Zongyuan Pan

Institute of Karst Geology, Chinese Academy of Geological Sciences, No. 50 Seven Stars Road, Guilin, Guangxi Province,541004,China, zypan@karst.acn.cn

\section{Xiaozhen Jiang}

Institute of Karst Geology, Chinese Academy of Geological Sciences, No. 50 Seven Stars Road, Guilin, Guangxi Province, 541004, China,jxz@karst.ac.cn

\section{Mingtang Lei}

Institute of Karst Geology, Chinese Academy of Geological Sciences, No. 50 Seven Stars Road, Guilin, Guangxi Province, 541004, China,lmt@karst.ac.cn

\section{Jianling Dai}

Institute of Karst Geology, Chinese Academy of Geological Sciences, No. 50 Seven Stars Road, Guilin, Guangxi Province, 541004, China, daijianling@karst.ac.cn

\section{Yuanbing Wu}

Institute of Karst Geology, Chinese Academy of Geological Sciences, No. 50 Seven Stars Road, Guilin, Guangxi Province, 541004, China,wuyb@karst.ac.cn

\section{Yongli Gao}

Center for Water Research, Department of Geological Sciences, University of San Antonio, One UTSA Circle, San Antonio, TX 78249,USA,yongli.gao@utsa.edu

\begin{abstract}
Sinkhole collapse has become a major geohazard in many karst areas. The development of monitoring and early warning technologies is essential to investigate mechanisms of sinkhole formation. This paper reviews latest research on monitoring and early warning technologies surrounding cover-collapse sinkholes. Monitoring the hydrodynamic conditions in areas susceptible of sinkhole collapse has proven to be useful to help understand the relationship of rainfall, surface water, and groundwater in karst areas. Monitoring hydrodynamic conditions of karst groundwater includes rainfall monitoring, groundwater level monitoring, air pressure monitoring, and groundwater quality monitoring. Observations from the monitoring system and known sinkhole collapses could be used to simulate and predict hydrogeologic, geologic, and atmospheric conditions favorable to sinkhole formation. Monitoring technologies of deformation for the overburden soil include Ground Penetrating Radar (GPR), Time Domain Reflectometry (TDR), and Brillouin Optical Time Domain Reflectometer (BOTDR). GPR is more suitable
\end{abstract}

to investigate relatively flat terrain with dry soil cover. TDR and BOTDR were more suitable for linearly distributed monitoring sites because of the cohesion between soil mass and optical fiber.

\section{Introduction}

Sinkhole collapse is a dynamic phenomenon, which usually takes place in karst areas (Kang, 1984). The total karst area in China reaches 3,650,000 km², which occupies more than one-third of the territorial area of China. In the past few decades, more than 3315 sinkhole collapse events were recorded (Kang, 1984). Most of these collapse events occurred in southwestern, central, and southern China. Sinkhole collapse became a major geohazard in many karst areas in China. The sinkhole hazard not only destroyed land and infrastructure but also impacted socioeconomic development and human lives and properties (Papadopoulou-Vrynioti, 2013). Due to subtle development and abrupt collapse, it is very difficult to predict and prevent sinkhole collapses. Therefore, monitoring and early warning technologies are crucial to prevent sinkhole collapse and to mitigate damage caused by sinkhole hazard. 


\section{Characteristics of Sinkhole}

Sinkhole collapse is a dynamic phenomenon, which is caused by the deformation and fracture of rocks and sediments. Influential factors on the deformation and fracture could be natural or human induced (Lei, 1998).

According to the lithological characteristics of collapsed substances, sinkhole collapses could be classified into three types: cavern collapse, soil cave collapse, and noncarbonate rock roof above carbonate bedrock collapse (Williams, 1983). According to Kang (1988), 96.7\% of sinkhole collapses were soil cave collapse in China (overburden material collapse) and mostly occurred in areas where the thickness of soil layer is less than $30 \mathrm{~m}$. The process of soil cave collapse involved four steps: (1) groundwater took away soil particles; (2) small soil void formed and enlarged; (3) soil cave expanded near ground surface; (4) the roof of soil cave collapsed. Therefore, three conditions including flowing groundwater, soluble bedrock, and non-cohesive soil exist in most cases of cover-collapse sinkholes. However, there was no warning before most sinkholes collapses. Even though many methods have been carried out to investigate sinkholes such as field surveys, geomorphological mapping, and borehole logging (Cooper, 2008; Gutierrez and Cooper, 2002). Spatial and temporal prediction of sinkhole was immature with little success. More practical technology and tools are needed to predict sinkhole collapses and to minimize casualties and property losses.

\section{Influential Factors on Cover-collapse Sinkhole}

Sinkhole development is mainly influenced by hydrodynamic conditions, characteristics of overburden materials, and the degree of karstification of underlying bedrocks (Wu, 1999). Sinkholes are more likely triggered by multiple factors. However, single factor could be predominant in certain sinkhole collapse event.

In general, groundwater plays a significant role in the process of forming soil voids and sinkholes. Investigations of hydrodynamic conditions in recent collapse events and physical experiments reveal that sinkholes mainly occurred in the process of groundwater level decline, groundwater level rise, and groundwater fluctuations around the boundary of soil and bedrock (Jiang, 2016). Wang (2000) stated that frequent fluctuations of groundwater level not only change the state and strength of overlying soil mass but also lead to alternating normal and negative pressures in the subjacent caves and soil voids, which eventually result in collapses.

Characteristics of overlying soil include composition, compactness, and permeability. Soil voids could form in sandy and gravelly soil because of lower cohesive force and tend to collapse after heavy rainfall (Zhu et al., 2000; Liu et al., 2000). The thicker the overburden sediment, the longer amount of time a cavity can grow, and the larger a cavity can become.

The degree of karstification of underlying bedrock is determined by the quantity and scale of cavities and fractures. Soil particles can move into cavities and fractures through the process of soil piping. If the underlying bedrock is highly karstified with large cavities and numerous fractures, the overburden soil and sediments could be easily eroded and form substantial voids and eventually trigger cover-collapse sinkholes.

\section{Monitoring Hydrodynamic Conditions of Karst Groundwater}

Monitoring hydrodynamic conditions of karst groundwater includes rainfall monitoring, groundwater level monitoring, air pressure monitoring, and groundwater quality monitoring.

\section{Rainfall Monitoring}

The recharge of rainfall and surface water would affect groundwater conditions. The fluctuation of groundwater could affect the condition and strength of overburden materials. Meanwhile, the air inside karst caves could be compressed or expanded when groundwater level fluctuated through cave conduits.

Therefore, rainfall monitoring is necessary. Rain gauge could be used to collect rain water and measure rainfall intensity. A typical rain gauge consists of event data logger and a tipping-bucket device. The rain gauge used for case studies in this paper collected rain water and recorded time, duration, rainfall amount, and temperature data. Data recording frequency was set every 10 minutes and the battery capacity could sustain at least 4 months.

\section{Groundwater Level and Air Pressure Monitoring}

The karst groundwater-monitoring network was established to monitor changes of groundwater level and temperature. Each monitoring site consisted of water pressure probe, cable, data logger, storage battery, timer, 
and data transmission module (Figure 1). Data logger was used to receive and store data of water pressure through the probe and transmitted data to terminal computer via data transmission module. Storage battery supplied electric power to data logger and data transmission module and connected to a solar panel for recharge. The installation of monitoring equipment involves the following steps: (1) drill a borehole and insert a perforated PVC pipe; (2) the depth of borehole and groundwater level are estimated so a suitable water pressure probe would be selected; (3) probe should be enclosed in a gauze bag filled up with sand; (4) the borehole near the ground surface would be sealed.

\section{Case Study 1 - Groundwater Monitoring in Dachengqiao, Ningxiang, China}

A groundwater monitoring network was established to monitor changes of groundwater in May 2013 in Dachengqiao, Ningxiang, Hunan Province, China (Figure 2). The goal of this case study is to examine the development of sinkhole collapses in relation to changes of groundwater level. The ultimate goals are to better understand the formation mechanism of sinkhole collapse and to forecast sinkhole collapse events in the future. Figure 2 illustrates groundwater level changes at site yr4-1. The daily precipitation on May 18, 2013 was $30.4 \mathrm{~mm}$. Groundwater level abruptly increased about $2 \mathrm{~m}$ and then fell back very rapidly after the rainfall even though the net change of groundwater level increased, which may indicate the overburden soil was disturbed and soil void collapse caused the anomaly of the level of groundwater. At 9:00 am on May 24, 2013, water table suddenly increased $3 \mathrm{~m}$ (Figure 3 ) and a $1 \mathrm{~m}$-diameter sinkhole formed on the east side of the monitoring station (Figure 4).

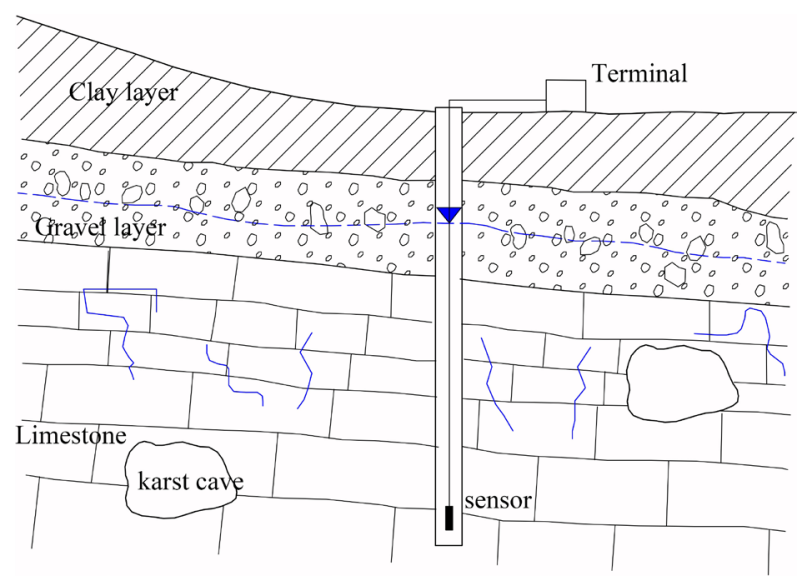

Figure 1. Schematic diagram of groundwater level monitoring.

\section{Groundwater Quality Monitoring}

Groundwater quality parameters include temperature, $\mathrm{pH}$, conductivity, and concentrations of cations and anions. A portable water quality meter was used to measure temperature, $\mathrm{pH}$ and conductivity of groundwater in the field. Additional water samples were collected using appropriate sampling bottles by following correct sampling protocols. These water samples were analyzed for cations and anions in the research lab at the Institute of Karst Geology.

Monitoring the hydrodynamic conditions would help understand the relationship of rainfall, surface water, and groundwater in karst areas. Observations from the system and known sinkhole collapses could be used to simulate and predict hydrogeologic, geologic, and atmospheric conditions favorable to sinkhole formation.

\section{Overburden Material Deformation Monitoring Ground Penetrating Radar (GPR)}

Ground penetrating radar (GPR) has been widely used in hydrological and engineering investigations. The

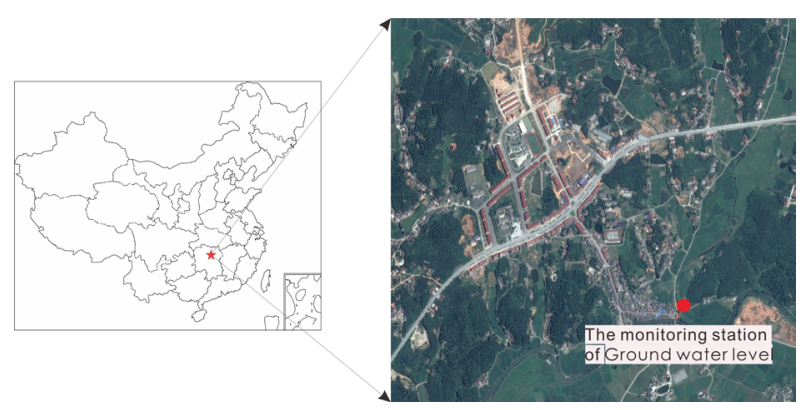

Figure 2. Location of Dachengqiao, Ningxiang, China.

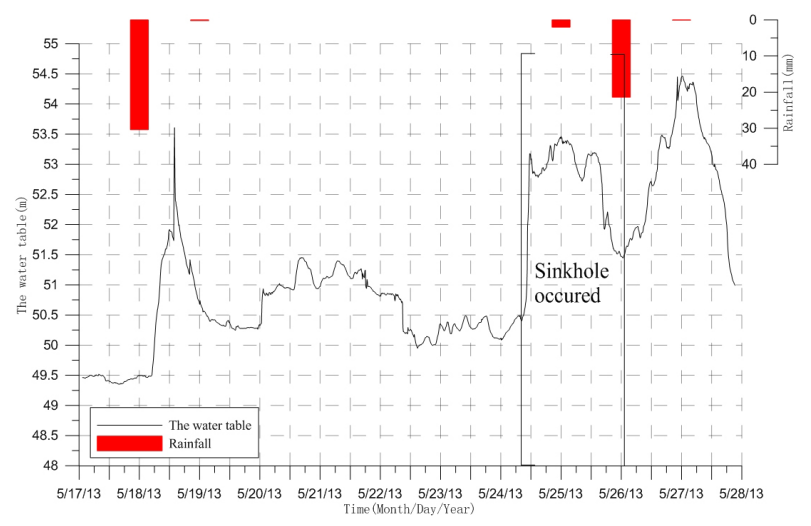

Figure 3. Drastic increase in water level of yr4-lin Dachengqiao, Ningxiang, China (5/17/2013-5/28/2013). 


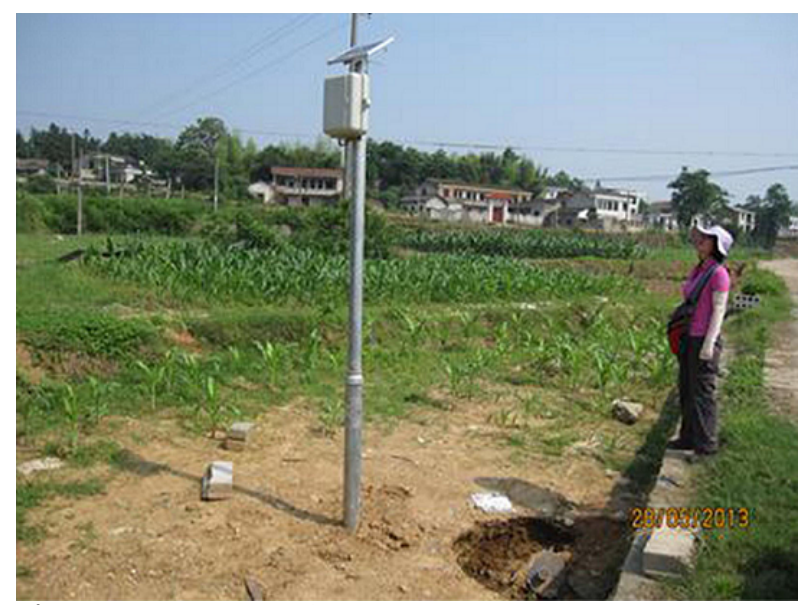

Figure 4. A small sinkhole collapse $11 \mathrm{~m}$ diameter) formed on the east side of monitoring site yr 4-1 lin Dachengqiao, Ningxiang, China.

MALA radar system consists of control unit, shielded antenna, electrical cable, and measuring wheel. GPR system transmits electromagnetic wave through its antenna. Portions of electromagnetic waves would be reflected to ground surface when electromagnetic wave encountered abnormal medium in the process of spreading underground. The reflected waves were analyzed through terminal machine. GPR was widely used to detect and monitor deformations in rock-soil layer of geohazard area (Zhang et al, 2000; Jiang et al, 2008; Xiong et al, 2014). The detection capability of GPR is limited by hydrogeological conditions and infrastructure. For example, the travel distance of radar is affected by groundwater level, metal object, and high-voltage wire in the study area. In general, GPR is more suitable to investigate relatively flat terrain with dry soil layer.

\section{Case Study 2 - Detecting soil voids along Guilin-Yangshuo Highway, Guangxi, China}

GPR was used to locate and characterize karst hazard zones within K9-K23 section of Guilin-Yangshuo highway in Guangxi, China (Figure 5) (Lei et al., 2011). Soil voids along the highway were detected by using a GPR with the $100 \mathrm{MHz}$ frequency (Figure 6). A total of 337 subsurface voids, $1-6 \mathrm{~m}$ in diameter, $1-5.5 \mathrm{~m}$ deep, and density up to 48 per $100 \mathrm{~m}$, were detected using GPR.

In this work, GPR, multi-electrode electric resistivity, and shallow seismic reflection were used for a preliminary survey. Comparison of the three geophysical methods indicates that GPR can detect subsurface voids in a more effective and timely manner.

\section{Time Domain Reflectometry (TDR)}

Time Domain Reflectometry (TDR) was first used for detecting the malfunctioned segment of telecommunication cable and electric transmission line in electric power industry. It was then used to measure water content of soil in the 1980s (Topp, 1985). O'Connor et al. (2001) installed TDR under a highway for real-time monitoring of ground deformation and changes. Chen et al. (2004) investigated TDR properties of coaxial cables under different test conditions and proposed valuable conclusions for practical applications. Jiang et al. (2011) conducted a series of geotechnical and material tests in both laboratory and field settings and proved that coaxial cable could be used to monitor and forecast karst collapse under suitable conditions. The coaxial cable grouted with cement mortar was paved under places where soil voids tend to occur. The coaxial cable with cement would be fractured by the impact of overlying soil at which the soil void underneath the coaxial cable developed to a certain scale (Figure 7). Location of soil void could be determined through the TDR curve image.
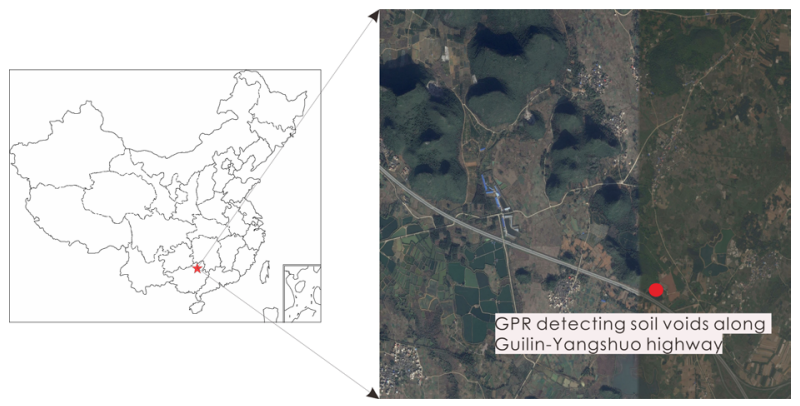

Figure 5. Location of Guilin-Yangshuo Highway, Guangxi, China.
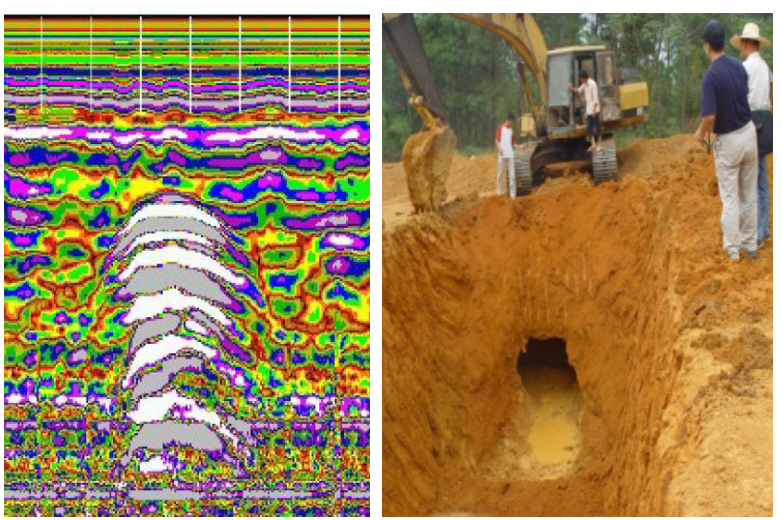

Figure 6. Detecting soil voids along GuilinYangshuo Highway, Guangxi, China. Left, hyperbolic anomaly in GPR profile; Right, soil voids after excavation. 


\subsection{Brillovin Optical Time Domain Reflectometer (BOTDR)}

Brillouin Optical Time Domain Reflectometer (BOTDR) is inbuilt the optical fiber in the rock-soil mass, where soil void or sinkhole collapse tend to occur. The deformation or fracture of rock-soil mass could be detected when the status of rock-soil mass changed. The location and development rate of soil void could be calculated to forecast potential karst collapse.

Tkach et al. (1986) came up with BOTDR technology. Horiguchi et al. (1995) measured strain- and temperatureinduced changes in Brillouin frequency shift. Bao et al. (2001) conducted a series of experiments both in the laboratory and outdoors and took temperature compensation into account for strain measurement. Their accuracy of strain measurement was improved to $5 \mathrm{~m}$. Jiang et al. (2006) applied BOTDR to measure soil deformation in the process of sinkhole collapse in a large-scale model experiment. The experimental results showed that BOTDR would be a reliable technology to monitor and predict sinkhole collapse or subsidence, especially along linear infrastructure constructions. Guan et al. (2012) found that key factors affecting the application of BOTDR included changes of stress field distribution, void size change during the formation of the void, and the difference of responding sensitivity to the stress field change among different optical fibers.

\section{Case Study 3 - Application of BOTDR to forecast soil void development in Chaoshan village, Tongling, Anhui, China}

BOTDR was used to forecast potential soil void development in the drainage area of Chaoshan village, Tongling, Anhui, China (Figure 8). A total of $500 \mathrm{~m}$ optical fiber was buried along a $1 \mathrm{~m}$ deep and $0.8 \mathrm{~m}$ wide trench. Optical fiber was fixed into the bottom of

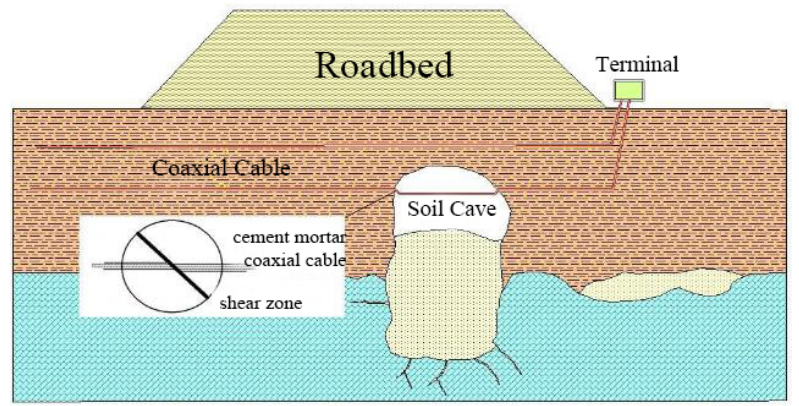

Figure 7. Schematic diagram of TDR monitoring technology for soil cave detection (Qin et al, 2010). the trench and then backfilled with soil. Observations in 2016-2017 from BOTDR showed no obvious soil deformation in the drainage area, which indicates normal soil deposition and compaction in the study area (Figure 9). No soil voids and sinkhole collapses occurred from field investigation during the same time in the study area. Results of BOTDR monitoring agree with field investigations.

At present, TDR and BOTDR were more suitable for linear investigation because of the cohesion between soil mass and optical fiber. On the other hand, the practical application of TDR or BOTDR was mainly focused on areas close to the optical fiber.

\section{Conclusions}

Due to subtle development and abrupt onset of covercollapse, it is very difficult to predict and prevent sinkhole collapses. Monitoring hydrodynamic conditions of karst groundwater has proven to be useful in cases of soil void development caused by rapid fluctuations of karst water table. GPR was very effective to detect soil voids in
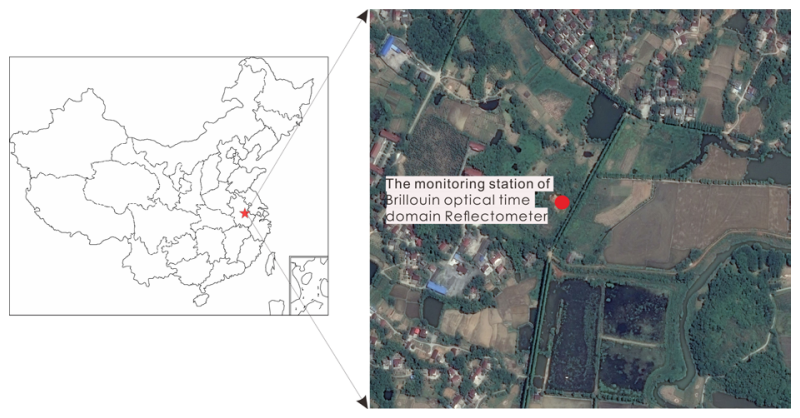

Figure 8. Location of Chaoshan village, Tongling, Anhui, China.

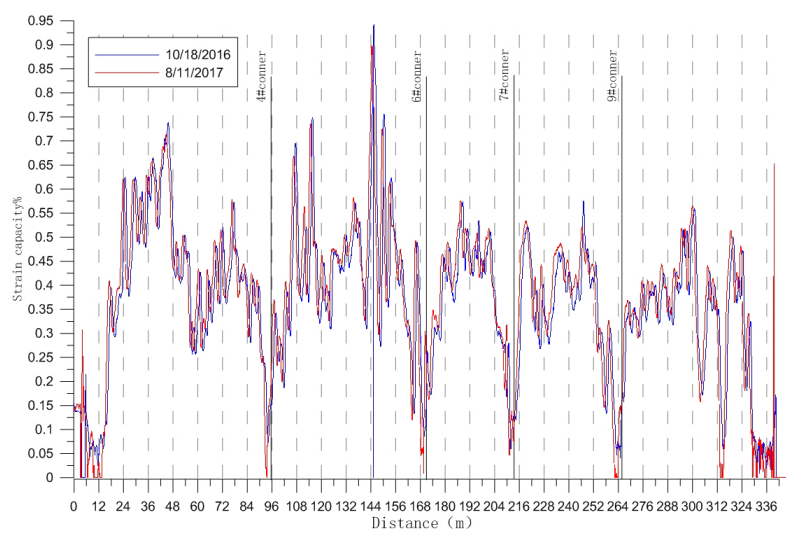

Figure 9. The strain capacity of BOTDR in Chaoshan village, Tongling, Anhui, China (10/18/2016-8/1 1/2017) indicates normal soil deposition and compaction. 
karst areas of relatively flat terrain with dry soil covers. TDR and BOTDR had some successes to monitor soil deformation along linear monitoring network. However, sinkholes are more likely triggered by multiple factors, joint application of more than 2 monitoring technologies would be necessary in many cases (Zeybek et al., 2015). Monitoring and early warning technologies are crucial to prevent sinkhole collapse and to mitigate damage caused by sinkhole hazards.

\section{Acknowledgements}

This work was supported by the National Natural Science Foundation of China (NSFC) (Grant No. 41472298 \& 41428202), China Geological Survey Project (Gran No. DD20160254), the National Youth Science Foundation of China (NYSFC) (Grant No.41402284). The collaborative research on sinkhole and soil void formation is also supported by the Center for Water Research in the University of Texas at San Antonio. We are grateful to an anonymous reviewer, managing editor (Ira Sasowsky), associate editors (Clint Kromhout and Ming Ye), and assistant editors (Mike Byle and Lewis Land) for the proceedings of the 15th Sinkhole Conference for their comments and suggestions to improve the quality of this paper.

\section{References}

Cooper AH. 2008. The GIS approach to evaporatekarst geohazards in Great Britain. Environmental Geology 53: 981-992.

Chen Y, Chen Y, Chen R, Liang Z. 2004. Testing study on applications of time domain reflectometry to slope monitoring. Chinese Journal of Rock Mechanics and Engineering 23 (16): 2748-2755 (in Chinese with English abstract).

Guan ZD, Jiang XJ, Gao M. 2012. A calibration test on optical fiber sensing device for karst collapse monitoring. Carsologica Sinica 31 (2): 173-178 (in Chinese with English abstract).

Gutierrez F, Cooper AH. 2002. Evaporite dissolution subsidence in the historical city of Calatayud, Spain: damage appraisal and prevention. Natural Hazards 25: 259-288.

Horiguchi T, Shimizu K, Kurashima T. 1995. Development of a distributed sensing technique using brillouin scattering. Journal of Light Wave Technology 13 (7): 1296-1302.

Jiang XZ, Lei MT, Gu WF. 2008. Soil cave monitoring and sinkhole prediction in linear engineering summarization. Carsologica Sinica 27 (2): 172-176 (in Chinese with English abstract).
Jiang XZ, Lei MT, Dai JL. 2011. A study of the monitoring deformation of sinkhole collapse using TDR time domain reflectometry. Hydrogeology and Engineering Geology 38 (1): 118-122 (in Chinese with English abstract).

Jiang XZ, Lei MT, Chen Y. 2006. An experiment study of monitoring sinkhole collapse by using BOTDR optical fiber sensing technique. Hydrogeology and Engineering Geology 33 (6): 75-79 (in Chinese and abstract in English).

Jiang XZ, Lei MT, Guan ZD. Character of water or barometric pressure jump within karst conduit in large strong drainage area of karst water filling mine in Dachengqiao, Ningxiang, Hunan. Carsologica Sinica 35 (2): 179-189 (in Chinese with English abstract).

Kang YR. 1984. Classification of land collapses in karst regions. Carsologica Sinica 2: 146-155 (in Chinese with English abstract).

Kang YR. 1988. Forming condition of land collapses in karst regions. Carsologica Sinica 7 (1): 9-18 (in Chinese with English abstract).

Kang YR.1989. On the mechanism of karst collapses. Geology of Guangxi 2 (2): 83-90 (in Chinese with English abstract).

Lei MT. 1998. Research on the present situation and developing tendency of karst collapse and techniques for its supporting. The Chinese Journal of Geological Hazard and Control 9 (3): 1-6.

Liu BC, Song Q, Chen XJ. 2000. Analysis on the features of the karst collapse in western region of Guilin city. Journal of Geological Hazards and Environment Preservation 11 (3): 200-203.

O’ Connor K, Clark R, Whitlatch D, Dowding C. 2001. Real-time monitoring of subsidence along I-70 in Washington, Pennsylvania. Transportation Research Record: Journal of the Transportation Research Board 1772 (1): 32-39.

Papadopoulou-Vrynioti K, Bathrellos GD, Skilodimou HD, et al. 2013. Karst collapse susceptibility mapping considering peak ground acceleration in a rapidly growing urban area. Engineering Geology 158 (8): 77-88.

Qin XL, Yan M, Jiang XZ. 2009. Application of ANSYS to early warning of soil cave evolution. Carsologica Sinica 28 (3): 275-280.

Tkach RW, Chraplyvy AR, Derosier RM. 1986. Spontaneous brillouin scattering for single-mode optical fiber characterization. Electronics Letters 22 (19): 1011-1013.

Topp GC. 1985. Measurement of soil water content using time-domain reflectometry (TDR): a field evaluation. Soil Science and Society of America Journal 49 (1): 19-24. 
Wang L. 2000. The relationship between groundwater activity and karstic collapse in the western regions of Guilin. Journal of Guilin Institute of Technology 20 (2): 106-111.

Wu YQ. 1999. Groundwater flow and geological hazards. Underground Space 19 (4): 303-316 (in Chinese with English abstract).

Williams PW. 1983. The role of the subcutaneous zone in karst hydrology. Journal of Hydrology 61: 1-3.

Xiong ZT, Zhao DJ, Wang MX, et al. 2014. The application of comprehensive geophysical prospecting in karst collapse investigation, Wuhan city. Resource Environment and Engineering 28 (2): 188-192.

Yu LP, Zhu P, Lei MT, et al. 2005. Monitoring technique and methods of the karst collapses. Carsologica Sinica 24 (2): 103-108.

Yuan J, Gao Z. 2010. Discuss on controlling and forming mechanism of Zaozhuang karst collapse. The Chinese Journal of Geological Hazard and Control 21 (4): 95-98.

Zhou J, Zhang YQ, Fang YG, et al. 2016. Analysis of joint action of water level fluctuation and rainfall on the influence of karst ground collapse. Journal of Water Resources and Architectural Engineering 14 (1): 218-222.

Zhang H, Lan Z, Zhang Y. 2000. The application of geological radar to the investigation of Shazhouba karst collapse in Ruijin. Geophysical and Geochemical Exploration 24 (6): 459-463.

Zeybek M, Ismail Sanlioglu, Ozdemir A. 2015. Monitoring landslides with geophysical and geodetic observations. Environmental Earth Sciences 74 (7): 6247-6263.

Zhu SZ, Chen JH, Chen XJ. 2000. Analysis of forming conditions and main influential factors of karst collapse in west urban district, Guilin city. Journal of Guilin Institute of Technology 20 (2): 100-105. 
166 NCKRI SYMPOSIUM 7 15TH SINKHOLE CONFERENCE 